\title{
DIFFERENT SHAPES OF THE HUMAN PARATHYROID GLANDS - A POSTMORTEM STUDY
}

\author{
MAHBUB $\mathrm{S}^{1}$, ARA $^{2}$, ALIM A ${ }^{1}$, NURUNNABI ASM ${ }^{1}$, AHMED R $^{3}$, BEGUM M $^{4}$
}

\begin{abstract}
:
Context: The parathyroid glands are very essential for survival. Parathyroid related clinical conditions such as parathyroid adenoma and hyperplasia are common. Different shapes of the human parathyroid glands have been identified. Knowledge of different shapes of the parathyroid gland is essential for surgeon, sonologist, pathologist for better diagnosis and management of parathyroid diseases.

Materials and Methods: A descriptive study was designed in the Department of Anatomy, Dhaka Medical College, Dhaka from January to December 2008 to see different shape of the parathyroid gland and was performed on post mortem parathyroid glands of 60 Bangladeshi people of different age, ranging from 15 to 75 years. A total of 207 parathyroid glands were taken from the cadavers. The samples were collected from the unclaimed dead bodies within 24-36 hours after death which were under examination in the Department of Forensic Medicine of Dhaka Medical College, Dhaka. Different shapes were observed by using a hand lens.

Results: Parathyroid glands were found to be oval (35.76\%), leaf shaped (27.43\%), spherical (24.76\%), tear-drop shaped (2.41\%), rod like (4.83\%), sausage like (1.93\%), pancake shaped (1.44\%) and bean shaped (1.44\%).
\end{abstract}

Key words: Parathyroid gland, shape of parathyroid.

J Dhaka Med Coll. 2009; 18(1) : 44-46

\section{Introduction:}

The parathyroid glands are very essential for survival, as the hormones secreted by the parathyroids regulates circulating ionized calcium and maintains the internal milieu ${ }^{1}$. Parathyroid related clinical conditions such as parathyroid adenoma and hyperplasia are very common and cause hypercalcaemia. Besides, iatrogenic removal of the parathyroids during thyroid surgery leads to hypocalcaemia and may be fatal ${ }^{2}$. Different shapes of the human parathyroid glands have been identified ${ }^{3}$. One of the important goals of the parathyroid surgery is recognition of normal parathyroid glands, as well as removal of the abnormal glands. But, sometimes small adenomas, thyroid nodules, normal or diseased lymph nodes or even fat can be mistaken for localization of the parathyroids. Therefore, recognition of the parathyroid glands, which appear in various shapes is much critical ${ }^{4}$. Knowledge of the shape of the parathyroid glands is necessary for it. It is also important for sonologists and pathologists to differentiate the normal parathyroid from any adenomatous or nodular growth, or lymph nodes whenever investigating the diseases of the thyroid, parathyroid or any swelling of the neck ${ }^{5}$. Knowledge of different shapes of the parathyroid gland is essential for surgeons, sinologists and pathologists for better diagnosis and management of parathyroid diseases.

\section{Materials and Methods:}

A descriptive study was designed to see the shape of the parathyroid glands in the Department of Anatomy, Dhaka Medical College, Dhaka. A total of 207 post mortem parathyroid glands of were collected from 60 Bangladeshi people of different age. The samples were collected from the unclaimed

1. M.Phil. Student, Department of Anatomy, Dhaka Medical College, Dhaka.

2. Professor and Head, Department of Anatomy, Dhaka Medical College, Dhaka.

3. Lecturer, Department of Anatomy, Dhaka Medical College, Dhaka.

4. Associate Professor, Department of Anatomy, Dhaka Medical College, Dhaka.

Correspondence : Dr. Sabiha Mahbub 
dead bodies which were under examination in the Department of Forensic Medicine of Dhaka Medical College, Dhaka. All the samples were collected within 24-36 hours of death without any sign of putrefaction, from medicolegal cases excluding hanging, poisoning, any cutting or crushing injury to neck region and known case of parathyroid disease. All the collected samples were brought to the Department of Anatomy and preserved in $10 \%$ formol saline for further study.

Different shapes were determined (Fig.-1) by using a hand lens and comparing with the figures of the glands as previously observed by Wang $(1976)^{3}$.
Ethical Clearance: This research work was approved by the Ethical Review Committee of Dhaka Medical College, Dhaka.

\section{Results:}

The findings of the shape of the parathyroid gland are presented in the Table-I.

In total, the parathyroid glands were found to be oval (35.76\%), leaf shaped $(27.43 \%)$, spherical $(24.76 \%)$, rod like (4.83\%), tear-drop shaped $(2.41 \%)$, sausage like (1.93\%), pancake shaped (1.44\%) and bean shaped (1.44\%) as shown in Fig. -2 .

Table-I:

Shape of superior and inferior parathyroid glands of right and left side $(n=207)$

\begin{tabular}{lcccccccc}
\hline \multicolumn{7}{c}{ Shape of parathyroid glands } \\
\cline { 2 - 8 } & \multicolumn{1}{c}{ Oval } & $\begin{array}{c}\text { Tear } \\
\text { drop }\end{array}$ & $\begin{array}{c}\text { Pan } \\
\text { cake }\end{array}$ & Spherical & Leaf & Sausage & Rod & Bean \\
\hline $\begin{array}{l}\text { Right Superior } \\
\text { (n = 59) }\end{array}$ & $22(37.2 \%)$ & $2(3.3 \%)$ & $1(1.6 \%)$ & $16(27.1 \%)$ & $14(23.7 \%)$ & $1(1.6 \%)$ & $2(3.3 \%)$ & $1(1.6 \%)$ \\
Left Superior & $18(34.6 \%)$ & $1(1.9 \%)$ & $1(1.9 \%)$ & $10(19.2 \%)$ & $16(30.7 \%)$ & - & $4(7.6 \%)$ & $2(3.8 \%)$ \\
$(\mathrm{n}=52)$ & & & & & & & & \\
$\begin{array}{l}\text { Right Inferior } \\
\text { (n = 47) }\end{array}$ & $17(36.1 \%)$ & $1(2.1 \%)$ & $1(2.1 \%)$ & $12(25.5 \%)$ & $15(31.9 \%)$ & $1(2.1 \%)$ & - & - \\
$\begin{array}{l}\text { Left Inferior } \\
\text { (n= 49) }\end{array}$ & $17(34.6 \%)$ & $1(2.0 \%)$ & - & $13(26.5 \%)$ & $12(24.4 \%)$ & $2(4 \%)$ & $4(8.1 \%)$ & - \\
\hline
\end{tabular}

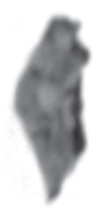

1

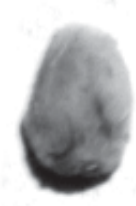

5

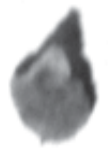

2

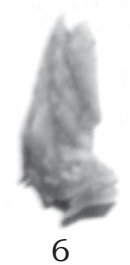

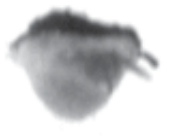

3

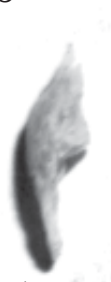

7

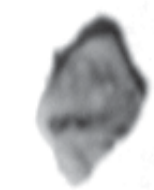

4

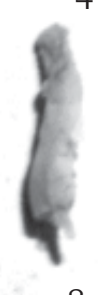

8

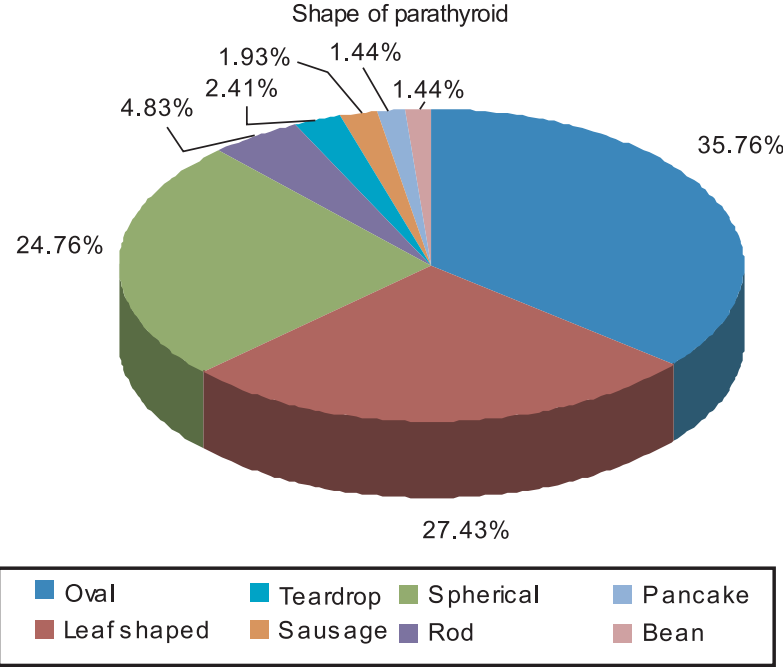

Fig.-2: Pie chart showing the frequency of different shapes of the parathyroid glands $(n=207)$.

shaped, 3. pancake shaped, 4. oval, 5. spherical
6. bean shaped, 7. sausage shaped, 8. rod like).

Fig.-1: Different shapes of the parathyroid glands seen through lens (1. leaf sha ped, 2. tear drop 


\section{Discussion:}

Huppert and Reading $(2007)^{6}$ stated that the normal parathyroid glands are typically oval or bean-shaped. Gartner and Hiatt (2006) ${ }^{7}$ stated that each parathyroid gland is a small, ovoid structure. According to Berkovitz (2005) ${ }^{8}$, the parathyroid glands are ovoid or lentiform structures. According to Becker et al. $(2001)^{9}$ the parathyroid glands are kidney bean shaped. Fawcett (1994) ${ }^{10}$ stated that the parathyroid glands are small ovoid bodies. Wang $(1976)^{3}$ stated that the parathyroid glands are of various shapes such as oval, spherical, leaf, pancake, tear drop etc. Occasionally a gland appears to be bean, sausage, or rod-shaped. There was no previous study of the shapes of the parathyroid glands available in our country. In the present study, most of the parathyroid glands were found to be oval shaped. However, leaf, spherical, tear drop, rod, sausage, pancake and bean shaped parathyroid glands were also found. The result of the present study has got more or less similarity with the findings of Huppert and Reading (2007) $)^{6}$, Gartner and Hiatt $(2006)^{7}$, Berkovitz (2005) ${ }^{8}$, Becker et al. $(2001)^{9}$, Fawcett (1994) ${ }^{10}$ and Wang (1976) ${ }^{3}$.

\section{Conclusion:}

The parathyroid glands are variable in their shape. Further studies with larger sample size, both peroperative and post mortem, are recommended.

\section{Acknowledgement:}

We would like to express our heartfelt thanks to the authority of Health, Nutrition \& Population Sector Programme (HNPSP) of Directorate General of Health Services (DGHS) of the Government of the People's Republic of
Bangladesh, and Dhaka Medical College, Dhaka for providing fund for this research work.

\section{References:}

1. Rosai J. Rosai and Ackerman's surgical pathology. Vol.1. $9^{\text {th }}$ ed. New Delhi: Elsevier Mosby; 2004. p.595-610.

2. Kumar V, Abbas AK, Fausto N. eds. Robbins and Cotran pathologic basis of disease. $7^{\text {th }}$ ed. New Delhi: Saunders; 2004. p.1183-9.

3. Wang CA. The anatomic basis of parathyroid surgery. Ann. Surg. 1976; 183: 271-5.

4. Grant CS. Surgical anatomy of the thyroid, parathyroid, and adrenal glands. In: Fischer JE, Bland KI, Callery MP, Clagett GP, Jones DB, LoGerfo FW, et al. eds. Mastery of surgery. Vol.1. $5^{\text {th }}$ ed. Philadelphia: Lippincott Williams \& Wilkins; 2007. p.388-97.

5. Graif M, Itzchak Y, Strauss S, Dolev E, Mohr R, Wolfstein I. Parathyroid sonography: diagnostic accuracy related to shape, location and texture of the gland. Br J Radiol. 1987; 60(713): 439-43.

6. Huppert BJ, Reading CC. Parathyroid sonography: Imaging and intervention. J Clin Ultrasound. 2007; 35: 144-55.

7. Gartner LP, Hiatt JL. Color textbook of histology. $3^{\text {rd }}$ ed. Philadelphia: W.B. Saunders; 2006. p.314-6.

8. Berkovitz BK. Neck and upper aero-digestive tract. In: Standring S, Ellis H, Healy JC, Johnson D, Williams A, Collins P, et al. eds. Gray's anatomy: the anatomical basis of clinical practice. $39^{\text {th }}$ ed. London: Elsevier Churchill Livingstone; 2005. p.564-5.

9. Becker KL, Bilezikian JP, Bremner WJ, Hung W, Kahn CR, Loriaus DL, et al. eds. Principles and practice of endocrinology and metabolism. $3^{\text {rd }}$ ed. Philadelphia: Lippincott Williams \& Wilkins; 2001. p.474-8.

10. Fawcett DW. Bloom and Fawcett - a textbook of histology. $12^{\text {th }}$ ed. New York: Chapman \& Hall; 1994. p.498-502. 